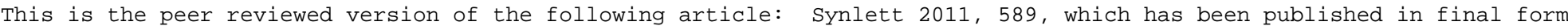
at https://www.thieme-connect.com/ejournals/abstract/synlett/doi/10.1055/s-0030-1259553. Copyright CGeorg Thieme Verlag Stuttgart. New York.

\title{
Cyclization of Aminocyclopropanes in Indole Alkaloids Synthesis.
}

\author{
Filippo De Simone and Jérôme Waser* \\ Laboratory of Catalysis and Organic Synthesis, Ecole Polytechnique Fédérale de Lausanne, \\ EPFL SB ISIC LCSO BCH 4306, 1015 Lausanne, (Switzerland) \\ Fax: (+41)21-693-9700 \\ E-mail: jerome.waser@epfl.ch \\ Received: The date will be inserted once the manuscript is accepted.
}

\begin{abstract}
The regioselective and diastereoselective cyclization of acyliminium intermediates generated from aminocyclopropanes on unprotected indole is presented. The recent results obtained in our group are compared with previous intermolecular reactions with aminocyclopropanes as well as with other cyclization methods involving iminium ions and unprotected indoles. A first speculative analysis of possible reaction mechanisms allows rationalizing the observed selectivity. The high potential of the method for the synthesis of natural alkaloids is demonstrated in the formal synthesis of aspidospermidine and the total synthesis of goniomitine.
\end{abstract}

Key words: Alkaloids, Cyclization, Indoles, Iminium, Aminocyclopropanes

Cyclization and cycloaddition reactions are important tools in organic chemistry to access the complex polyclic core of natural products. ${ }^{1}$ Both concerted pericyclic processes or reactions involving reactive intermediates can be envisaged. The former has the advantage of a low activation barrier, which allows mild conditions. It is limited usually to substrates containing correctly aligned orbital systems (DielsAlder, electrocyclic cyclization, sigmatropic rearrangements). The use of reactive intermediates such as carbocations or radicals opens further pathways for cyclization. To make them accessible under mild conditions, the introduction of destabilizing elements in the starting material is an important strategy. Cyclopropanes are well-suited for this task, due to their high strain energy (26-29 $\mathrm{Kcal} / \mathrm{mol}$ ). Especially donor-acceptor substituted cyclopropanes are easily opened under mild conditions to form reactive zwitterionic intermediates. $^{2}$ They can be considered as homologous equivalents of olefins in diverse annulation and cyclization reactions. After the pioneering work of Stork, Danishefsky and Corey in the 1970 's, ${ }^{3}$ progress in reactions involving activated cyclopropanes was slow. An important exception is represented by the work of Wenkert and Reissig. ${ }^{4}$ In the last 10 years, the potential of cyclopropanes in catalysis has been increasingly recognized, either in Lewis or Brønsted acid mediated [3+2] cycloadditions, or in ring-opening reactions with nucleophiles or electrophiles (Scheme 1). ${ }^{5}$

The introduction of cyclopropanes into classical substrates used in pericyclic reactions can lead to unprecedented reactivity. For example, it is well known that the Cope rearrangement of divinylcyclopropanes proceeds much faster than in the absence of the strained ring. ${ }^{6}$ The Nazarov cyclization is another important pericyclic reaction. ${ }^{7}$ Catalytic and asymmetric versions of the reaction were developed in the course of the last 20 years. $^{8}$ Substitution of a double bond by a cyclopropane in divinyl ketones leads to the formal homo-Nazarov cyclization. Despite its promising potential for the synthesis of cyclohexenones, the homo-Nazarov cyclization has been only scarcely studied and the strong conditions needed have limited its applicability. ${ }^{9}$

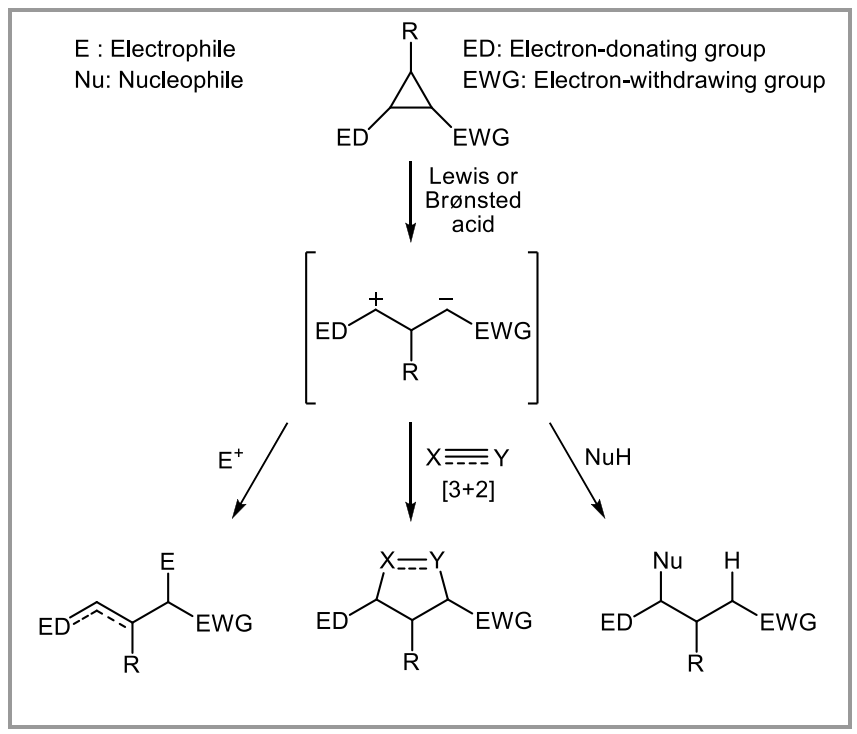

Scheme 1 Reactivity of activated cyclopropanes.

In 2009, we demonstrated the use of activated cyclopropanes in the first catalytic homo-Nazarov cyclization. ${ }^{10}$ Using a heteroatom substituted double bond or a heterocycle as nucleophile and an electron rich aromatic group on the cyclopropane, we were able to achieve cyclization under mild conditions (Scheme 2). The design of these cross-polarized substrates was based on successful works in catalytic Nazarov cyclizations. ${ }^{11}$

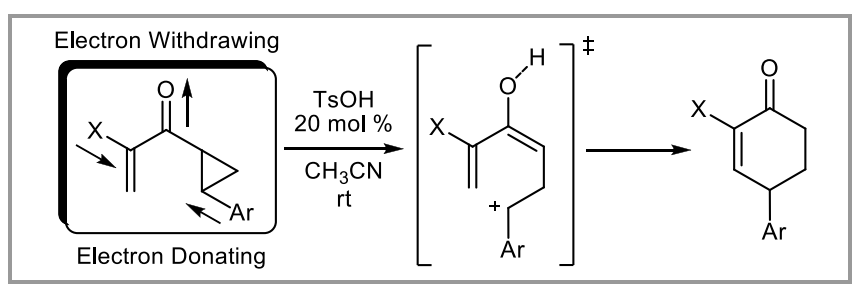

Scheme 2 Catalytic formal homo-Nazarov cyclization. 
Mechanistic investigations indicated a rate-limiting cyclopropane opening step to form a carbocationic intermediate prior to cyclization. Interestingly, Yadav and co-workers reported that a $\beta$-silyl effect could also be used to promote the homo-Nazarov reaction, but in this case a super-stoichiometric amount of strong Lewis acid was required. ${ }^{12}$

The discovery of the first catalytic conditions for the formal homo-Nazarov cyclization was an important progress, but the scope of the reaction was still strongly limited by the requirement for an aromatic stabilizing group on the cyclopropane. A heteroatom would also allow an easy formation of the carbocation and at the same time increase the range of structures accessible. ${ }^{13}$ Activated aminocyclopropanes could be used as precursors of acyliminium ions in order to access the common aminocyclohexane scaffold of highly bioactive indole alkaloids, such as strychnine (1) and vinblastine (2) (Scheme 3).

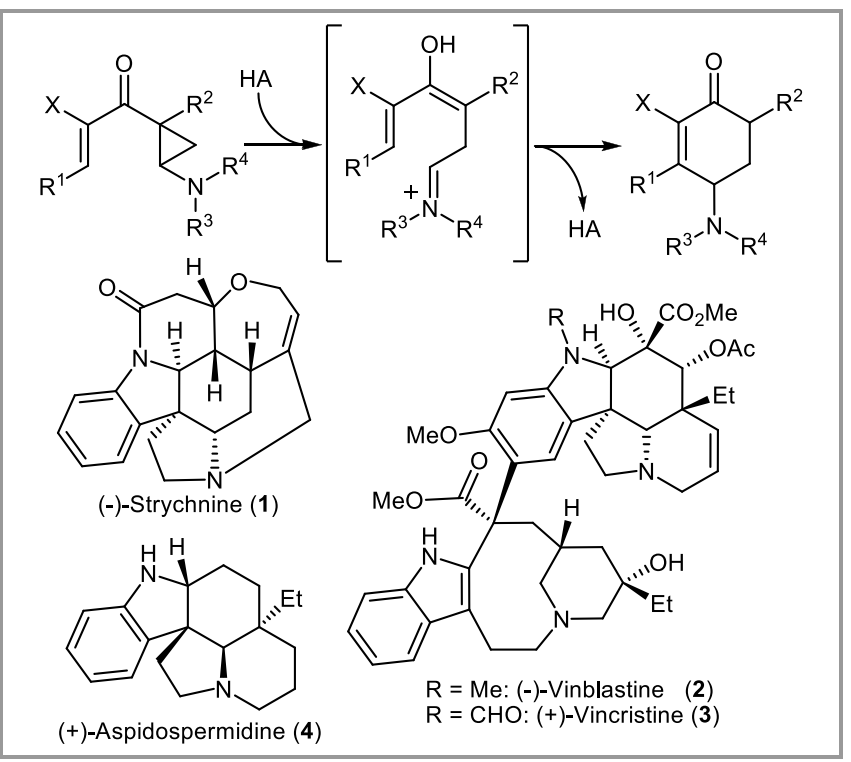

Scheme 3 Cyclization of aminocyclopropanes and potential targets.
In contrast to other donor-acceptor cyclopropanes, there are only few examples of intermolecular additions involving aminocyclopropanes (Scheme 4). ${ }^{14}$ In 1988 Wenkert reported the use of aminocyclopropane $\mathbf{5}$ as an acyliminium precursor for intermolecular addition reactions. ${ }^{14 \mathrm{~b}}$ The approach was used in the synthesis of the alkaloid dehydroaspidospermidine. Cyclopropane opening and addition to indole were done in two distinct reaction steps, and a 2:1 mixture of diastereoisomers 8 was obtained. No example of intramolecular cyclization had been reported prior to our work..$^{15}$ As a first target for our studies, we selected the aspidosperma alkaloid aspidospermidine (4), as it contains the common tetracyclic scaffold of many alkaloids and would allow a direct comparison with the stepwise intermolecular strategy of Wenkert. ${ }^{14 \mathrm{~b}}$

We started our studies with aminocyclopropane 9, accessible in 8 steps from $\delta$-valerolactam. We decided to use the $\mathrm{NH}$ free indole to minimize the use of protecting groups. For the aminocyclopropane, we settled on a benzyloxycarbonyl (Cbz) group on the nitrogen, as it should remove enough electron-density to impair stability to the aminocyclopropane, but still allow accessing the cationic intermediate. Furthermore, the $\mathrm{Cbz}$ group is easily removed under mild conditions. To our delight, the cyclization worked well under our previously developed conditions $(20 \mathrm{~mol} \%$ toluenesulfonic acid in acetonitrile) ${ }^{10}$ and $74 \%$ yield of cyclized product was obtained. Careful NMR analysis of the crude mixture revealed a 1.6:1 mixture of $\mathrm{C} 3$ (10) and N1 (11) cyclization products. Fortunately, the choice of the right cyclization conditions allowed us to control the regioselectivity of the cyclization. The use of a polar solvent (acetonitrile) in combination with a soft Lewis acid (copper(II) triflate) afforded C-C bond formation while a strong Brønsted acid (toluenesulfonic acid) in non polar solvent (dichloromethane) favored the attack on the indole nitrogen generating the $\mathrm{C}-\mathrm{N}$ bond.

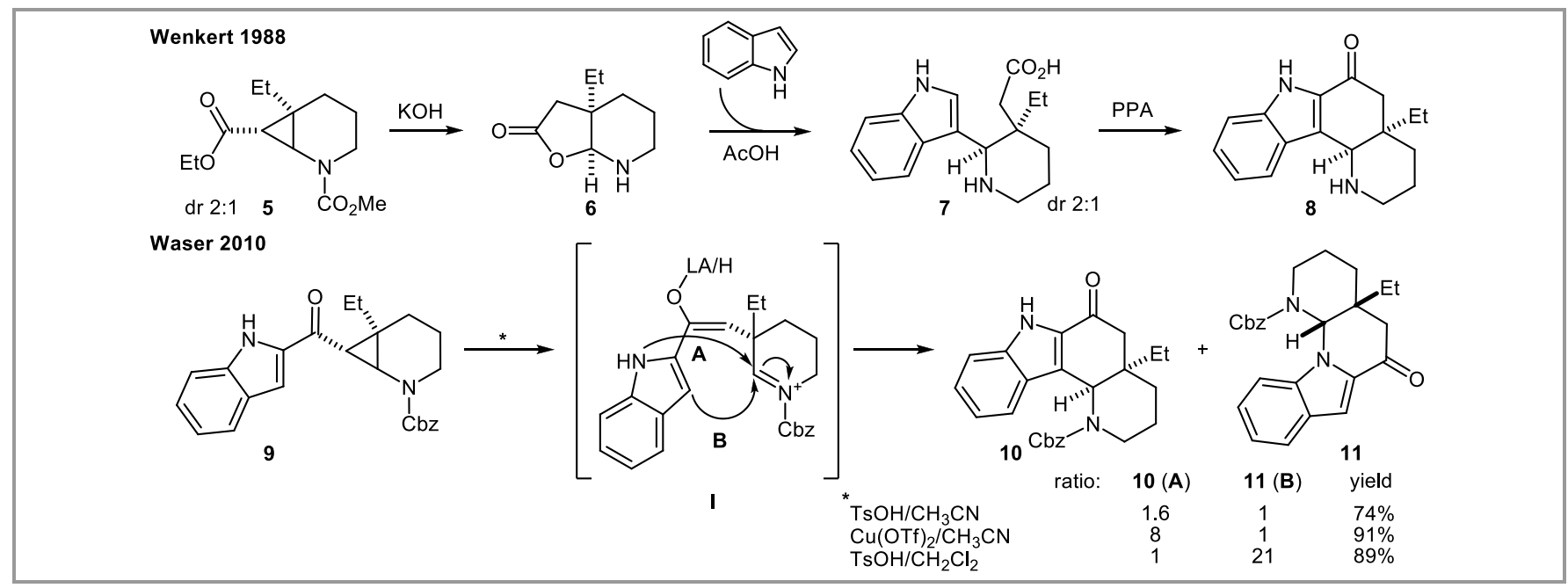

Scheme 4 Intermolecular and intramolecular reactions of acyl iminium ions with indoles. 
One possible explanation for the observed selectivity is based on the hard/soft reactivity of the formed intermediates. The use of $\mathrm{Cu}(\mathrm{OTf})_{2}$ would lead to the formation of a copper-bond enolate, which would favor reaction at the softer $\mathrm{C}-3$ indole position. The use of a polar solvent like acetonitrile should stabilize the charged iminium intermediate. Charge-controlled reaction with the nitrogen atom would consequently become slower in comparison with addition to the carbon atom, which is expected to have a higher HOMO coefficient. In contrast, a non-coordinating solvent together with a strong Brønsted acid will generate a "harder" intermediate with a rapid chargecontrolled reaction on nitrogen. The regioselectivity with the copper catalyst could also be rationalized by formation of a chelate complex between the oxygen and the nitrogen of indole. Such coordination is expected to be relatively weak, as the nitrogen lone pair of indole is part of the aromatic system. Moreover using the cyclization conditions affording 10, it was possible to convert the tetracyclic scaffold $\mathbf{1 1}$ into the aspidospermidine precursor $\mathbf{1 0}$, but no reaction was observed when $\mathbf{1 0}$ was submitted to the reaction conditions leading to $\mathbf{1 1}$. It appears consequently that $\mathrm{C}-\mathrm{N}$ bond formation is occurring under kinetic conditions, whereas $\mathrm{C}-\mathrm{C}$ bond formation would be thermodynamically favored. Both regioisomers were obtained as pure diastereoisomers. A first simple analysis of the possible transition states for the reaction allows rationalizing the observed selectivity
(Scheme 5). For the formation of the observed cis fused ring systems $\mathbf{1 0}$ and 11, it is possible to draw a transition state leading directly to a chair conformation in the product (IIa and IIc). In contrast, the only possible transition state leading to a trans product gives first a twist conformation, which is higher in energy (IIb and IId). Consequently, a classical Fürst-Plattner stereocontrol could be at the basis of the observed high stereoselectivity.

Regioselective cyclizations on non protected indoles involving iminium ions have not been extensively investigated. Rare examples in literature have shown how difficult it is to control the attack between the indole nitrogen and $\mathrm{C} 3$ carbon under mild conditions. Already in 1969, Joule and co-workers observed selective cyclization of iminium intermediates in the synthesis of dasycarpidone (14) and uleine (15) (Scheme 6). ${ }^{16}$ Under basic conditions, N-cyclization was observed when starting from deconjugated enamine 16, and C-cyclization was observed using acidic conditions. The interconversion from N1 to C3 cyclization products (17 and $\mathbf{1 8}$ ) was also observed with acid. Unfortunately, harsh conditions were required, and the yields were much lower when the ethyl substituent present in the natural product was introduced (5-30\%). The original work of Joule was done using iminiums as intermediates, and later more efficient cyclization was observed when acyliminiums were used.

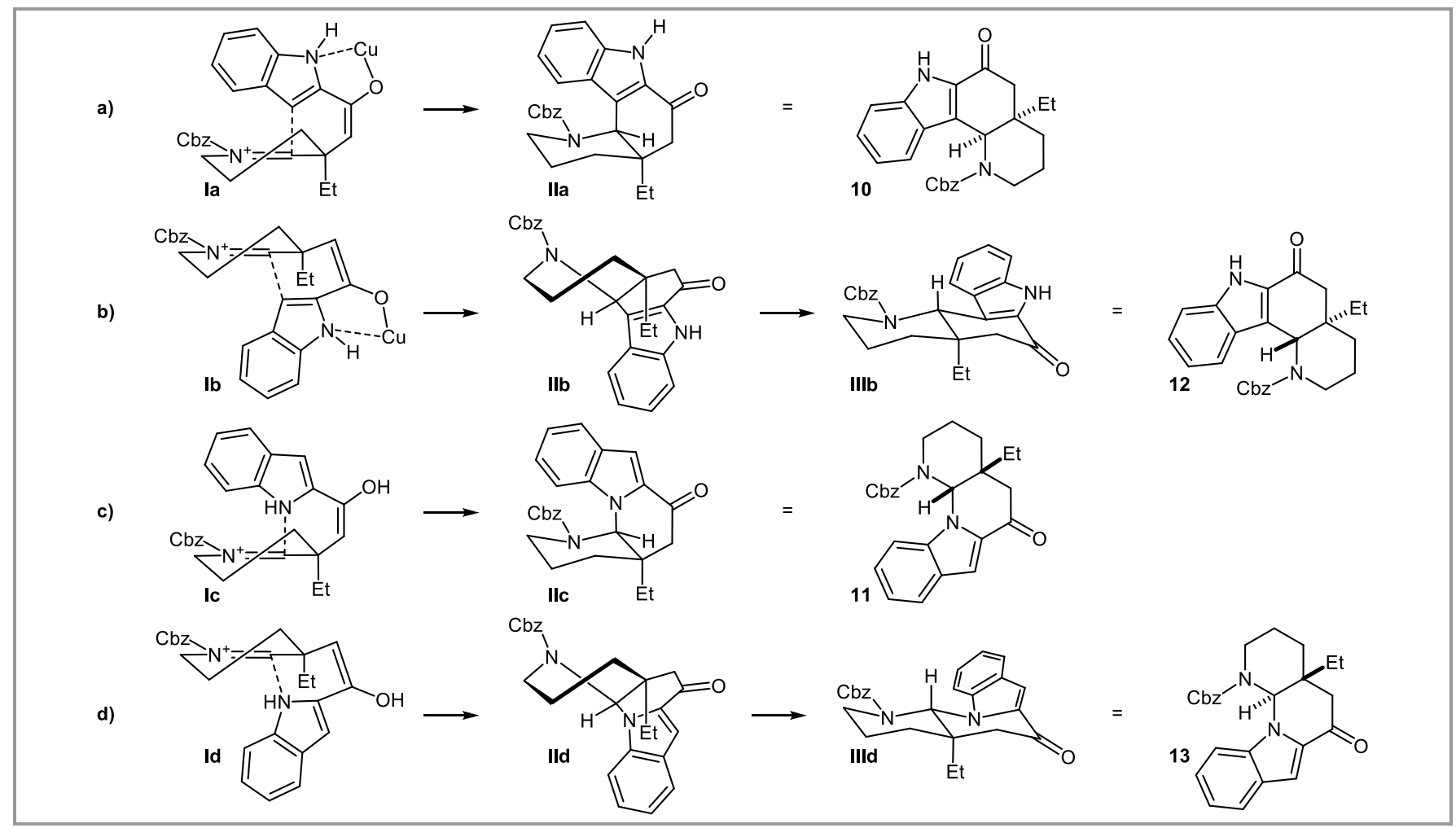

Scheme 5 Speculative transition states for the cyclization reaction. 
Rubiralta and co-workers used the reduction of imides to access the reactive intermediate, and a 3:1 mixture of $\mathrm{N}$ to $\mathrm{C}$ cyclization (20 and $\mathbf{2 1}$ ) was obtained in high yield. ${ }^{17}$ Isomerization to the thermodynamic product 21 was again possible under acidic conditions. Bosch, Amat and co-workers generated the acyl iminium from a chiral half aminal 22, and in this case C3 cyclization was observed exclusively. ${ }^{18}$ In both works, only the non natural 20-epi scaffold could be accessed, as the cyclization was not efficient for the other diastereoisomer. The work of Rubiralta and coworkers in the aspidosperma series is closest to our own work. ${ }^{19}$ Using their reductive approach, they were able to obtain the N-cyclization product 25 in $73 \%$ yield. Isomerization to the tetracyclic core of aspidospermidine $\mathbf{2 6}$ was again possible under acidic conditions. Finally, the use of indole aminals as starting materials for intra- or inter-molecular additions of nucleophiles has been studied more in details by Diez, Bonin and co-workers. ${ }^{20}$

Our method using aminocyclopropanes as acyl iminium precursors complements well the existing approaches, as it proceeds under mild conditions and does not require strong Lewis acids or reducing agents. Furthermore, both the $\mathrm{C} 3$ and the N1 cyclization products can be obtained in high yields in a single step just by changing the reaction conditions.
Removal of the Cbz group in $\mathbf{1 0}$ allowed us to finish a formal synthesis of aspidospermidine (4), as intermediate $\mathbf{8}$ had already been used by Wenkert. ${ }^{14 \mathrm{~b}}$ The versatility of our methodology was further demonstrated in the total synthesis of goniomitine $\mathbf{2 9}$ (Scheme 7). The indole intermediate 27 was cyclized in high yield in the presence of para-toluenesulfonic acid in dichloromethane. A sequence of reduction, acetylation and deprotection afforded goniomitine 29 in 13 linear steps and an overall yield of $11 \%$ starting from $\delta$-valerolactam. ${ }^{15}$ Preliminary biological assays have shown an interesting antiproliferative activity of goniomitine against several cancer cell lines. ${ }^{21}$

In summary, our recent work inspired by a formal homo-Nazarov reaction resulted in a new access to acyliminium intermediates for the synthesis of indole alkaloids. Control of the regioselectivity of the cyclization reaction on $\mathrm{N} 1$ or $\mathrm{C} 3$ position of indole was possible under mild conditions. The methodology could be applied to the formal synthesis of aspidospermidine (4) and the total synthesis of goniomitine (29). When considering the importance of acyl iminium as reactive intermediates for the synthesis of nitrogen-containing compounds, the method is expected to have a high potential for applications in other cyclization and annulation processes.

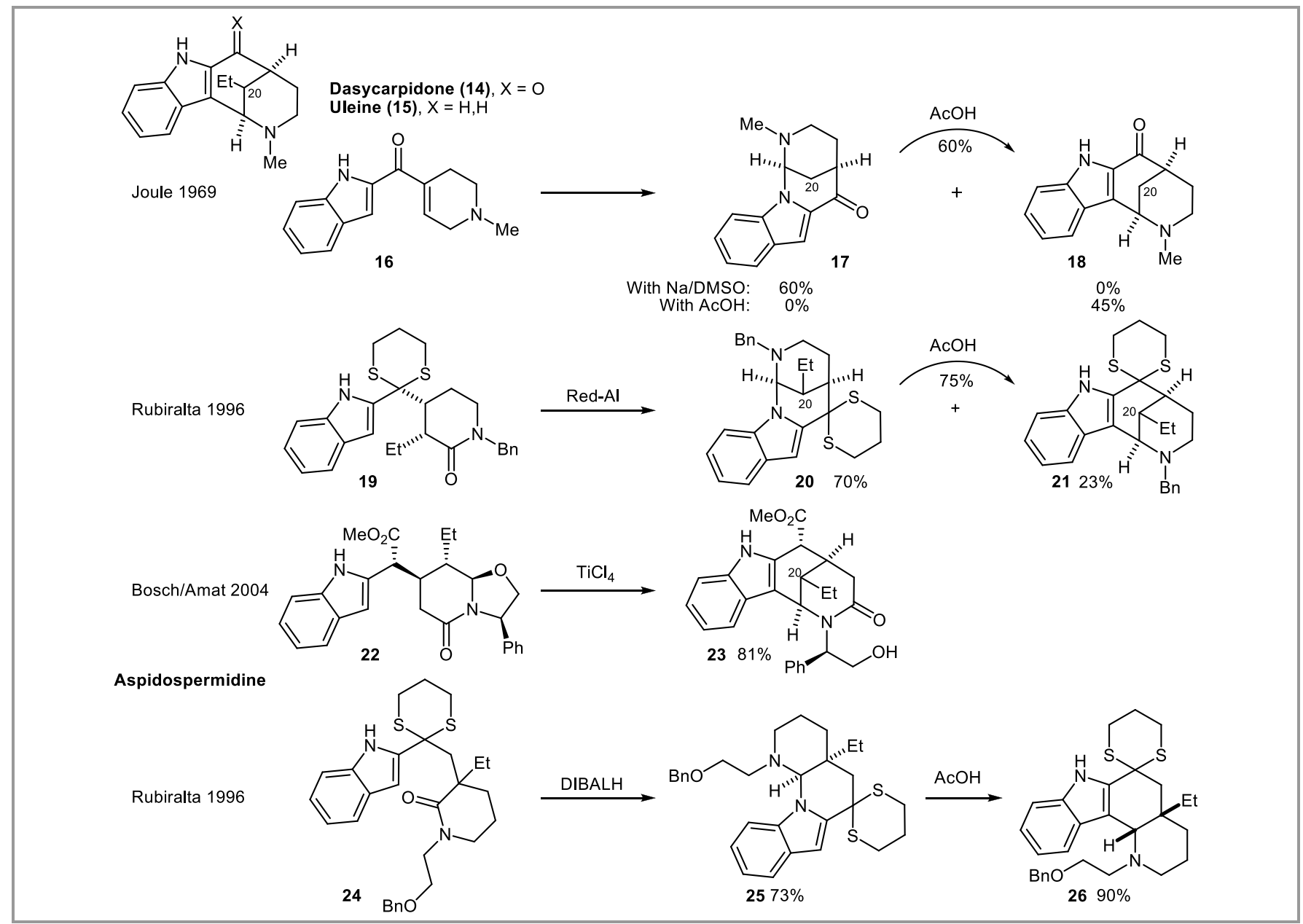

Scheme 6 Examples of cyclization of iminium on indole 


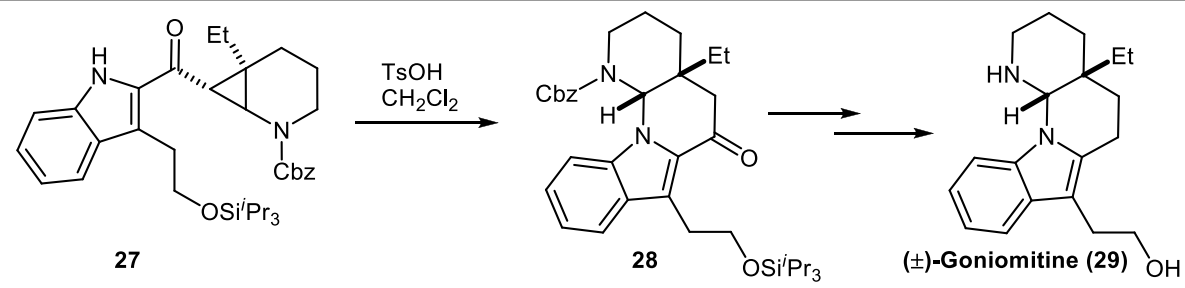

Scheme 7 Total synthesis of goniomitine.

\section{Acknowledgment}

The EPFL is acknowledged for financial support.

\section{References}

(1) Ma, S. M. In Handbook of Cyclization Reactions, Wiley-VCH, Weinheim, 2009.

(2) (a) Reissig, H. U.; Zimmer, R., Chem. Rev. 2003, 103, 1151. (b) Gnad, F.; Reiser, O. Chem. Rev. 2003, 103, 1603. (c) Yu, M.; Pagenkopf, B. L., Tetrahedron 2005, 61, 321. (d) Carson, C. A.; Kerr, M. A. Chem. Soc. Rev. 2009, 38, 3051. (e) De Simone, F.; Waser, J. Synthesis 2009, 3353. (f) Lebold, T. P.; Kerr, M. A. Pure Appl. Chem. 2010, 82, 1797.

(3) (a) Stork, G.; Marx, M. J. Am. Chem. Soc. 1969, 91 2371. (b) Stork, G.; Gregson, M. J. Am. Chem. Soc. 1969, 91, 2373. (c) Stork, G.; Grieco, P. A. J. Am. Chem. Soc. 1969, 91, 2407. (d) Corey, E. J.; Balanson, R. D. Tetrahedron Lett. 1973, 3153. (e) Danishefsky, S. Acc. Chem. Res. 1979, 12, 66.

(4) (a) Wenkert, E.; Alonso, M. E.; Buckwalter, B. L.; Chou, K. J. J. Am. Chem. Soc. 1977, 99, 4778. (b) Wenkert, E. Acc. Chem. Res. 1980, 13, 27. (c) Reissig, H. U.; Hirsch, E. Angew. Chem., Int. Ed. Engl. 1980, 19, 813. (d) Brückner, C.; Reissig, H. U. Angew. Chem., Int. Ed. Engl. 1985, 24, 588.

(5) For a few leading references, see: (a) $\mathrm{Yu}, \mathrm{M}$.;

Pagenkopf, B. L. J. Am. Chem. Soc. 2003, 125, 8122.

(b) Yu, M.; Pagenkopf, B. L. Org. Lett. 2003, 5, 5099.

(c) Young, I. S.; Kerr, M. A. Org. Lett. 2004, 6, 139. (d) Young, I. S.; Williams, J. L.; Kerr, M. A. Org. Lett. 2005, 7, 953. (e) Pohlhaus, P. D.; Johnson, J. S. J. Org. Chem. 2005, 70, 1057. (f) Parsons, A. T.; Johnson, J. S. J. Am. Chem. Soc. 2009, 131, 14202. (g) Parsons, A. T.; Smith, A. G.; Neel, A. J.; Johnson, J. S. J. Am. Chem. Soc. 2010, 132, 9688.

(6) Piers, E. In Comprehensive Organic Synthesis, Trost, B. M., Editor-in-Chief; Pergammon Press: New York, 1991; Vol. 5, 971.

(7) (a) Nazarov, I. N.; Zaretskaya, I. I., Izv. Akad. Nauk. SSSR. Ser. Khim 1941, 211. (b) Habermas, K. L.; Denmark, S. E.; Jones, T. K. Org. React. (N. Y.) 1994, 45, 1-158.

(8) (a) Jones, T. K.; Denmark, S. E. Helv. Chim. Acta 1983, 66, 2377. (b) Liang, G. X.; Trauner, D. J. Am. Chem. Soc. 2004, 126, 9544. For reviews, see : (a) Frontier, A. J.; Collison, C., Tetrahedron 2005, 61, 7577. (b) Pellissier, H., Tetrahedron 2005, 61, 6479. (c) Tius, M. A. Eur. J. Org. Chem. 2005, 2193. (d) Nakanishi, W.; West, F. G. Curr. Opin. Drug Discov. Dev. 2009, 12, 732.

(9) (a) Murphy, W. S.; Wattanasin, S. Tetrahedron Lett. 1980, 21, 1887. (b) Murphy, W. S.; Wattanasin, S. J. Chem. Soc. Perkin Trans. 1 1981, 2920. (c) Murphy, W.
S.; Wattanasin, S. J. Chem. Soc. Perkin Trans. 11982 , 1029. (d) Tsuge, O.; Kanemasa, S.; Otsuka, T.; Suzuki, T. Bull. Chem. Soc. Jpn. 1988, 61, 2897. For a review, see: (e) De Simone, F.; Waser, J. Chimia 2009, 63, 162

(10) De Simone, F.; Andres, J.; Torosantucci, R.; Waser, J. Org. Lett. 2009, 11, 1023.

(11) He, W.; Herrick, I. R.; Atesin, T. A.; Caruana, P. A.; Kellenberger, C. A.; Frontier, A. J. J. Am. Chem. Soc. 2008, 130, 1003 .

(12) Yadav, V. K.; Kumar, N. V. Chem. Commun. 2008, 3774.

(13) The introduction of an ester group in alpha position to the ketone also allows a further polarization of the cyclopropane and an extension of the scope. (a) Saget, T.; De Simone, F.; Waser, J. unpublished results. (b) Patil, D. V.; Phun, L. H.; France, S. Org. Lett. 2010, 12, 5684.

(14) (a) Wenkert, E.; Halls, T. D. J.; Kwart, L. D.; Magnusson, G.; Showalter, H. D. H. Tetrahedron 1981, 37, 4017.(b) Wenkert, E.; Hudlicky, T. J. Org. Chem. 1988, 53, 1953. (c) Kaufman, M. D.; Grieco, P. A. J. Org. Chem. 1994, 59, 7197. (d) Grieco, P. A.; Kaufman, M. D. J. Org. Chem. 1999, 64, 7586.

(15) De Simone, F.; Gertsch, J.; Waser, J. Angew. Chem., Int. Ed. 2010, 49, 5767.

(16) Jackson, A.; Wilson, N. D. V.; Gaskell, A. J.; Joule, J. A. J. Chem. Soc. C 1969, 2738.

(17) (a) Diez, A.; Castells, J.; Forns, P.; Rubiralta, M.; Grierson, D. S.; Husson, H. P.; Solans, X.; Fontbardia, M. Tetrahedron 1994, 50, 6585. (b) Forns, P.; Diez, A.; Rubiralta, M.; Solans, X.; FontBardia, M. Tetrahedron 1996, 52, 3563.

(18) (a) Amat, M.; Perez, M.; Llor, N.; Escolano, C.; Luque, F. J.; Molins, E.; Bosch, J. J. Org. Chem. 2004, 69, 8681.

(19) Forns, P.; Diez, A.; Rubiralta, M. J. Org. Chem. 1996, 61,7882.

(20) Cutri, S.; Diez, A.; Bonin, M.; Micouin, L.; Husson, H. P. Org. Lett. 2005, 7, 1911.

(21) The biological assays were done in the laboratory of Prof. Jürg Gertsch at the University of Bern in the framework of a COST CM0804 (Chemical Biology with Natural Products) collaboration. 
Cyclization of Aminocyclopropanes in Indole Alkaloids Synthesis.
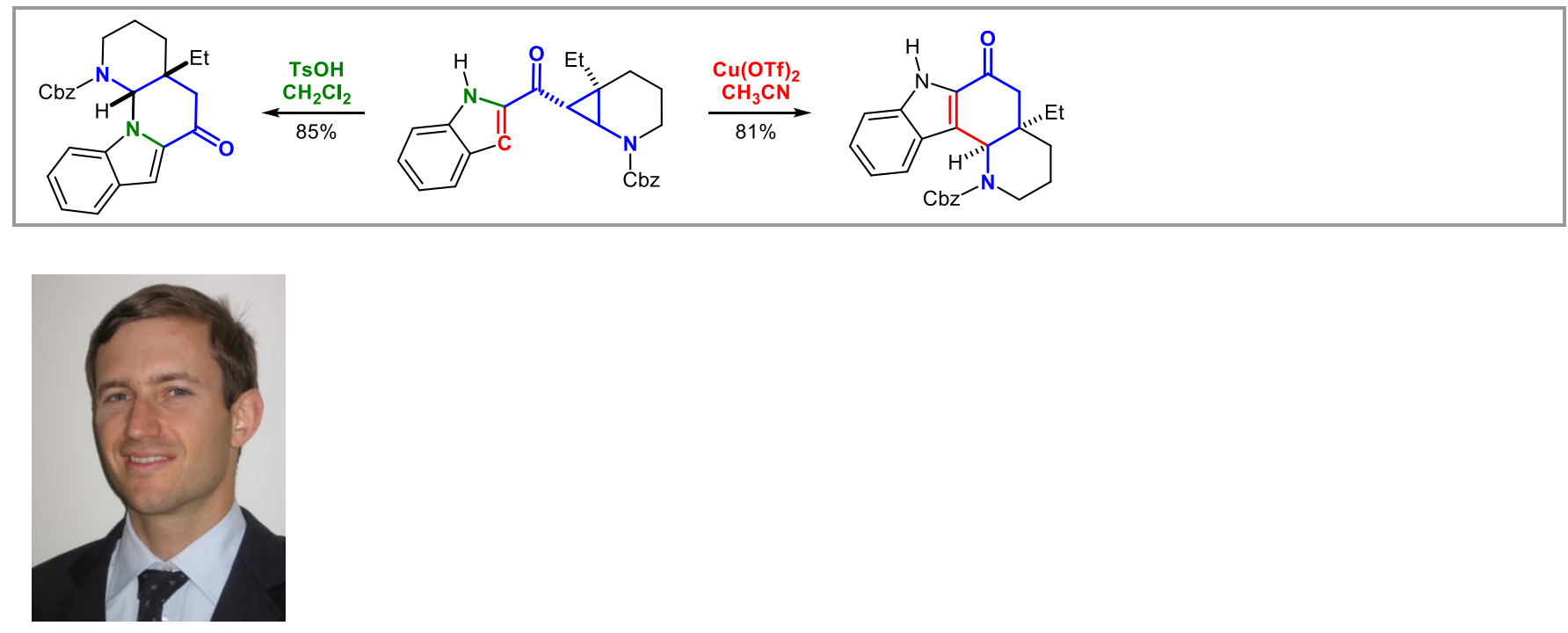

Jérôme Waser was born in Sierre, Valais, Switzerland. He studied chemistry at ETH Zurich and obtained his Diploma in 2001. In 2002, he started his PhD studies at ETH Zurich with Prof. Erick M. Carreira, working on the development of metal-catalyzed amination reactions of olefins. In 2006, he joined Prof. Barry M. Trost at Stanford University and accomplished the total synthesis of the diterpene Pseudolaric Acid B. Since October 2007, he is working as tenuretrack assistant professor at EPF Lausanne, focusing on the development and application of catalytic methods based on cyclopropanes and hypervalent iodine reagents for the synthesis of bioactive compounds. 